\title{
DET FÖRBJUDNAS LOCKELSE
}

\author{
Maria Sandel
}

Maria Sandel (1870-1927) är en av de första proletärförfattarna i Sverige och har kallats för en proletariatets Fredrika Bremer. ${ }^{1}$ Hon var med om att lägga grunden för en kulturrörelse som skulle komma att förnya den svenska litteraturen och producera både akademiledamöter och nobelpristagare, men själv gjorde Maria Sandel aldrig någon klassresa. Hon kom från fattig arbetarklass och stannade kvar där livet ut även om hon på äldre dagar kunde hanka sig fram på sitt skrivande.

Maria Sandel levde i mycket små omständigheter och fick börja arbeta redan i tolvårsåldern. Under några ungdomsår var hon hembiträde i USA men flyttade sedan hem igen och levde tillsammans med sin mor i en nödbostad på Kungsholmen. Båda var döva. De försörjde sig genom att sticka kläder på maskin i hemmet, samtidigt som de drev en liten kvartersbutik. Fattigdomen i kombination med dövheten och en allt sämre syn kringskar Maria Sandels rörelsefrihet och hon rörde sig sällan utanför hemkvarteren. Men det hindrade henne inte från att vara aktiv såväl politiskt som konstnärligt. Hon medarbetade flitigt i Social-Demokraten och Morgonbris och det var faktiskt hon som gav den senare tidningen dess namn. Hon skaffade sig också kontakt med flera av tidens ledande vänsterintellektuella: Ellen Key, Martin Koch och Hjalmar och Anna Branting.

Maria Sandel skrev om arbetarkvinnornas dagliga kamp för att få ihop till mat, kläder och hyra, om hemarbetet för textilindustrins räkning, om förhållandena på fabrikerna, om grovgöra i de rikas hem, om långa arbetsdagar och kvinnolöner som inte räckte till livets nödtorft. Hon skrev om klassamhället och om konflikter mellan 
arbetare och arbetsköpare. Hon skrev om maktförhållandena mellan könen och om missbrukande, misshandlande män. I de världar hon skildrade måste också männen slita ont, men trots att deras lön var mycket högre än kvinnornas användes den ofta bara för männens eget bruk eller missbruk, så att kvinnorna i praktiken ändå blev ensamförsörjare för barnen. Det finns en klassklyfta mellan könen i Maria Sandels berättelser där alltför många män tar för sig av sina privilegier på kvinnornas och barnens bekostnad. Världen hade sällan skildrats på detta sätt förut.

Sandel väjde inte för livets mörka sidor men hade också blick för det komiska och för vardagens glädjeämnen. Det finns ofta en djup solidaritet mellan kvinnorna i hennes berättelser. Det kan handla om gemenskap mellan grannar och arbetskamrater, om förhållandet mellan mor och barn eller om en inneboende och hennes hyrestant. Individerna är utsatta och sårbara, särskilt de ogifta mödrarna. Ensamma skulle de gå under, men tillsammans kan kvinnorna få en öken av fattigdom att blomma. De hjälps åt såväl praktiskt som ekonomiskt och kan trolla fram ett slags alternativa familjer där man delar livets sorg och glädje med varandra. ${ }^{2}$

Det finns temperament i dessa skildringar av livet i hemmen, på fabrikerna och på gatorna och de kryddas med snabba replikskiften och dråplig humor. ${ }^{3}$ Visst hade det funnits arbetarskildringar i litteraturen även tidigare, men de hade för det mesta fokuserat männens värld, berättats från ett uppifrånperspektiv och dessutom haft en sentimental och moraliserande ton. ${ }^{4}$ Sandels texter vittnar om djup förtrogenhet med de miljöer hon skildrade. De bär det självupplevdas prägel.

Sandel skrev sällan om romantisk kärlek, utan mera om sexualiteten som en urkraft som förändrar kvinnornas liv, inte så mycket av känslomässiga skäl som av materiella. Sexualiteten kan på kort tid förvandla en självständig och bekymmersfri ung kvinna till en utsatt, ogift mor eller en arbetarhustru med alltför många munnar att mätta. Den kan leda till prostitution och misshandel likaväl som till gemenskap och ett gott äktenskap. Sexualiteten i dessa berättelser är nästan alltid av heterosexuell art, men i romanen Droppar i folkhavet (1924) finns ett intressant undantag från den regeln. ${ }^{5}$ 
Det vore värt en egen studie att fundera över hur samkönade relationer skildras i den tidiga arbetarlitteraturen. Inte sällan förlades det samkönade begäret på ett klichébetonat sätt till dekadenta överklassmiljöer, där människor som lever ett liv med droger och allsköns utsvävningar intresserar sig för arbetarklassungdomar. Så är det i Martin Kochs Guds vackra värld (1916), en roman som bygger på en svartvit moral där samkönad sexualitet är hårt knuten till prostitution, droger, kriminalitet, narcissism, egoism och klassförräderi.

Men proletärlitteraturen innehåller också exempel på motsatsen. I debutromanen Kvinnor och äppelträd (1933) tecknade Moa Martinson ett ömsint porträtt av vänskapen mellan mor Sofi och Fredrika, två kvinnor som har gift sig för pengars skull men fått sina drömmar om välstånd och trygghet grusade. Mor Sofi har femton barn och Fredrika inga alls, eftersom hon inte tål sin man. Trötta efter veckans slit börjar de bada tillsammans och något sådant har man aldrig hört talas om i bygden. Det finns varm närhet i kvinnornas nakenhet och gemenskap, om än kanske inte i erotisk mening. Byborna vet inte vad de ska tro och kallar dem för "såna där", vad de nu menar med det. Kanske att de är karltokiga, kanske att deras relation är innerligare och sinnligare än vad som anses vara passande.

\section{Moral och omoral}

Centralfiguren i Droppar i folkhavet, Gerda Spant, är en kärlekstörstande arbeterska. Hon förälskar sig i den kriminelle Ulrik, som utövar en stark dragningskraft på kvinnor utan att själv vara särskilt intresserad. Det betonas att han är av tattarsläkt - Maria Sandel, som var nytänkande i så många avseenden, var i detta fall alltså lika fördomsfull som andra. Han utnyttjar och förnedrar Gerda på alla tänkbara sätt, också sexuellt. Han tvingar henne "att ge sig hän i könsliga utsvävningar, perversa uttryck för en uppjagad brunst". 6 Ordet "pervers" används på flera ställen i romanen om heterosexuella aktiviteter. Här är ett annat exempel:

Ulrik Isberg hade med den sista gemensamma nattens perversa 
utsvävningar sörjt för att vämjelsen över denna sida av könslivet blev en bundsförvant med det ädla i hennes natur, som kämpade mot sinnligheten, mot de förledande minnena av de kärleksstunder i hans famn, då hjärta och sinnen givit sig hän i ren lidelse. (150)

Vrakad, vräkt och havande hamnar hon sedan hos fru Hägg, "morsan" kallad. Gerda blir inneboende hos henne och mellan de båda kvinnorna "uppspirade en stark, oförstörbar sympati" (80). Tillsammans börjar de bygga upp en ny familj, där Gerdas dotter blir allas älskling. "Morsan" har inte mycket gott att säga om män, även om hon älskar sin egen son över allt annat. "Karlar, de är jordens ogräs." (126) "Ka-a-rarrr! Duktiga - men svinpälsar." (127) Hon fantiserar om att vetenskapen en gång ska hitta på ett sätt att göra män överflödiga; "kvinnorna reder sig allt bättre ekonomiskt, de mår bättre av att vara ensamma." (126)

Sandels romaner är ofta uppbyggda som en serie korta berättelser, som hålls samman genom miljön och det tematiska innehållet. I Droppar i folkhavet är det sexualitet och vänskap som är bärande teman. Alla centrala gestalter i romanen ges ett slags erotisk innehållsdeklaration. Gerda Spant har ett hett blod, får vi veta, men efter katastrofen med Ulrik Isberg lär hon sig att kontrollera det. För andra varmblodiga kvinnor i romanen går det sämre. "Morsan" besväras däremot inte av några erotiska begär och det gör inte hennes väninna Bina Tjäder heller. "Morsan" och hon tänker olika om det mesta men förenas av föraktet för "ka-a-rarr!" och sitt ointresse för det erotiska.

Flera av romanens dialoger handlar uttryckligen om sexualitet. I kapitlet "Lydia avslöjar det som är allmänt känt" är det preventivmedel och sexualmoral som står på dagordningen. Den unga Lydia avverkar den ena fästmannen efter den andra men lyckas ändå undvika graviditet. Hon pläderar glatt för kvinnors rätt att ha ett utsvävande sexliv och tycker att äktenskapet är en överskattad inrättning. "För det riktiga är naturligtvis att man lever som hanar och honor, när man är det. För som gossarna brukar säga, vi människor är ju egentligen bara djur allihop." (132) Lydia framställer sina idéer, 
hämtade från bland andra Ellen Key, på ett osmält sätt och framstår på det hela taget som ganska korkad. Som läsare inbjuds man att skratta åt såväl Lydia som hennes filosofi och någon sanningssägare är hon inte.

Det kan vara intressant att ha Lydia i minnet vid läsningen av kapitlet "Hetärer", där den lesbiska relationen skildras, för det finns paralleller mellan de båda kapitlen. Lydia tror sig kunna ha erotiska relationer med män på jämlika villkor, men texten undergräver hennes auktoritet och gör henne till en utnyttjad fjolla. Män tar mest och kvinnor ger mest i den form av relationer hon pläderar för. Kvinnorna riskerar att bli ogifta mödrar och att förlora sitt sociala kapital medan männen egentligen inte riskerar någonting. Gränsen mellan det acceptabla och det mindre acceptabla i Sandels sexualmoral går inte vid frågan om äktenskap, utan vid frågan om ansvarstagande. Det handlar inte om sipphet och moralism, utan om omsorg om varandra och andra.

Kvinnorna i kapitlet "Hetärer" är prostituerade och lever i en helt annan typ av ekonomi. Själva arbetet är visserligen så otrevligt för dem att den ena, Naima, kolkar i sig sprit för att stå ut, men yrket gör dem ändå socialt oberoende av män. Kvinnorna anser sig kunna utnyttja den ojämlika könsordningen till sin egen fördel, även om de får betala ett högt pris för sin frihet. Erotiken, den som finns till för sin egen skull, delar de med varandra. Med män umgås de bara för vinnings skull och de kallar männen för "djur", "kräk", "kreatur" och andra mindre smickrande saker. Den obetänksamma Naima kallar dem "asgamar", men då säger Sonja spetsigt att hon måste tänka mer på sitt bildspråk. Om de besökande männen är "asgamar" - fåglar som livnär sig på as - vad är då de själva? Inför denna fråga blir Naima förvirrad:

- O, vad jag önskar att jag vore karl.

- Jaså, gör du det, svarade Sonja med fattning. Det har jag växt ifrån för länge sedan. Jag är mycket nöjd med att vara kvinna.

- Ja det är klart att du ska vara originell i det också. Karlarna ha det bättre, säger jag, de är helt och hållet fria.

- Det tycker jag var originellt sagt av en kvinna med din erfa- 
renhet. Nog vet du att mannen är slav under sina sexuella begär, följaktligen kvinnans träl. (213)

Sonja är den som brukar få rätt i diskussionerna, men här håller Naima fast vid sin åsikt att männen har det bättre. Sonja säger:

- Det finns så mycket som talar för motsatsen, lilla du. Jag ska bara anföra ett skäl, det som du har lättast att förstå: Mannen är ju den som ger ställning i samhället, försörjning och dylikt. Nå, bör han då inte vara bra inbilsk för att kunna tro sig vara älskad för sin egen skull? (213-214)

Sonja beskriver relationen mellan man och kvinna som en transaktion där den ena parten ger sex medan den andra ger antingen bara pengar, som i prostitution, eller pengar och social ställning, som i äktenskap. Och Sonja lever som hon lär. Först säljer hon sig som prostituerad, och sedan ingår hon ett passande äktenskap, medan Naima inte kan hushålla med sina resurser. Hennes obetänksamhet och spritbegär gör henne till en dålig förhandlare.

Sonjas cyniska analys av transaktionerna mellan könen kan läsas som ett korrektiv till de idéer om kärleken som Lydia tidigare framförde. Det heterosexuella begäret kan förstås vara ömsesidigt, men relationer med män lönar sig sällan för kvinnorna vare sig man räknar i pengar eller i socialt ansvarstagande. Enligt "morsan" och Bina Tjäder är männen helt enkelt ganska överflödiga.

\section{Hetärer}

Gerda Spant kommer till de båda prostituerade kvinnornas bostad i sin egenskap av hemsömmerska. "Morsan" tycker visserligen inte om att Gerda går dit - "Såna där, sade morsan om dem" - men Gerda har en annan åsikt. "Ty bättre arbetsgivare kunde icke Gerda tänka sig." (194) De uppskattar hennes arbete, är generösa mot henne och den ena av dem, Sonja, har "en utpräglat artistisk smak" som Gerda kan lära sig mycket av. Men det finns också något annat i Gerdas relation till Sonja, något som inte har med några praktiska 
överväganden att göra: "Hon kände sig dessutom dragen till henne, påverkad av det stolta men intagande i hennes väsen." Sonja uppträder som en dam, till skillnad från sin väninna. Hushållerskan berättar att Sonja bokstavligen har plockat upp Naima från gatan.

$[\mathrm{H}]$ on hade också antytt orsaken: ett erotiskt förhållande mellan de två hetärerna. Men den upplysningen kunde hon ha sparat, ty Gerda begrep inte ett dyft. Hon hade varit för lite med i fabrikssladdret för att vara underkunnig i snett och vint ... (196)

Det erotiska momentet i relationen är alltså explicit och vi får veta att det tisslas och tasslas om denna form av kärlek även på fabrikerna. Gerda kanske inte riktigt förstår vad det hela handlar om, men berättaren ser till att läsaren gör det.

Naima får sig ett och annat tjuvnyp av berättaren, precis som vi tidigare såg Lydia få det. Sonja skildras däremot som en intelligent och värdig människa, samtidigt som hon framställs som en uttalat erotisk person med förmågan att locka fram dolda begär hos andra.

I hennes sovrum fanns blott en enda tavla - Gerda brukade tänka; en för mycket. Hon förstod att det var konst, eftersom fröken Glimmer icke skulle tålt ett fuskverk i sitt rum, men - . Driften sjöd upp hennes blod, brännande, pockande att tillfredsställas, blott hon fick ögonen på målningen, och till den drogos de obevekligt... (195)

Vad tavlan föreställer får läsaren aldrig veta. Kanske är motivet lesbiskt. Kanske inte. För Gerda är bilden hur som helst upphetsande.

Sonja är av god familj, men någon förklaring till varför hon har valt att prostituera sig ges aldrig. Hon är på många sätt en dekadent klichéfigur av det slag som både bildkonsten och skönlitteraturen under fin de siècle var så rik på, men väl inkorporerad i romanen ger författaren henne ett eget liv.` Det finns när det gäller Sonja en "undran i betraktande av den låga sociala ställning hon intog och förefintliga möjligheter till en helt olika och högre". (195) Vi får veta att Sonja som ung träffade "morsans" son på ett sanatorium och 
att deras kärlek varit lika ömsesidig som kysk. Och på bokens sista sidor får vi veta att hon gifter sig med en annan man. Men däremellan är hon sexuellt utmanande - i förhållande till flickvännen, men också i förhållande till Gerda och läsaren. Hon är en fallen ängel.

Naima framställs som en helt annan typ. Hon är en "cynisk, sentimental slarva, i grunden egoistisk men ytligt vänlig och godhjärtad”. (195) Hon har hamnat i prostitution för att hon är så svag för sex, sprit och lyx. Även Naima är en klichébild av den prostituerade kvinnan, men en kliché som är hämtad från andra diskurser än dekadensens litteratur. Hon passar till exempel utmärkt in i flera av de kategorier som Socialstyrelsen konstruerade i en rapport 1925 om kvinnor som hamnat i klammeri med myndigheterna. Här delas de kvinnliga tvångsarbetarna in i typer som sedan sorteras in i överoch underavdelningar, alltså ungefär så som insekter och andra djur brukade beskrivas i vetenskapen. Beroende på i vilken form Naima råkar vara kunde hon passa in i kategorier som "alkoholister", "demimonder", "gatflickor" och "berglärkor" - den sista termen avser det som beskrivs som "bottensatsen" av de gatuprostituerade. Det finns ytterligare en kategori där Naima kunde rymmas, nämligen de "Psykiskt höggradigt abnorma". Denna grupp beskrivs så här:

Gruppen innefattar bl.a. imbecilla, debila, infantila, sinnessjuka och hysteriska individer. Till densamma hava ock hänförts den s.k. brutala typen samt kvinnor med nymfoman läggning ävensom en del starkt homosexuella och andra psykopatiska individer. ${ }^{\text {b }}$

Som så ofta förr och senare hamnar gruppen homosexuella som synes i dåligt sällskap. Det korta citatet säger också mycket om den klassificeringsiver som styrde tanken hos de sociala och rättsvårdande myndigheterna vid denna tid.

Naima lever ur hand i mun och låter sig räddas av Frälsningsarmén när hon emellanåt har sjunkit alltför djupt i sprit och elände. Hon saknar sinne för det som är god smak i romanen och såväl Sonja som berättaren gör sig ofta lustiga på hennes bekostnad. Naimas rum är belamrat med tingeltangel och över hennes stora säng hänger en bonad, som hon själv har broderat, med texten: "Flitig var 
och du skall vinna, hälsa munterhet och bröd." (196) Att hon låter dessa ord trona över den säng där hon bedriver sin prostitutionsverksamhet blir förstås komiskt.

Naima har många egenskaper gemensamma med Lydia, hon med alla fästmännen, och med den psykologi som gäller i Sandels textvärld är de båda kvinnorna samma typ. Båda är komiska figurer som pratar snabbare än de tänker. Men det finns mer värme i porträttet av Naima och hon har fått några av romanens absolut roligaste och vassaste repliker. Dessutom intar hon hjälterollen i en kontrovers med sedlighetspolisen i slutet av kapitlet.

En dag råkar Gerda komma in till Sonja och Naima när de ligger alldeles nakna i varandras armar. "- Vad i all min dar, har fröknarna gått till sängs på nytt", utropar hushållerskan inför denna åsyn. "Mun mot mun lågo de två omslingrade i sängen. Det bjärtgröna sidentäcket var hopknycklat vid fotändan bland snövitt linne och spetsar. Naimas halmgula flättofs släpade i sängmattans vita päls.” Som synes är det knappast fråga om något systerligt gemensamhetssovande. Nakenheten, närheten och det hopknycklade täcket skvallrar om aktiv erotik. Vi får också reda på att nattduksbordet är "belamrat med porterbuteljer, glas, cigaretter och en obeskrivlig sak, jämte frälsningsarméns tidning". Scenen är en dekadent ekfras till Gustave Courbets "Sömnen", 1866. Vad den där obeskrivliga saken är får läsaren aldrig veta. Är det något som har med de båda kvinnornas profession att göra? Eller med deras gemensamma erotik? Gerda känner "en vämjelse, vars orsak hon inte begrep, rummet, luften där och framförallt de två kvinnorna i sin nakenhet, tycktes förhatliga. Omöjliga att uthärda.” (198) Men hon hämtar sig förvånansvärt snabbt från denna reaktion och är uppenbart road av de båda kvinnornas sällskap. Utan att tveka tar hon deras parti när de hotas av sedlighetspolisen.

De båda älskande blir inte nämnvärt generade över att Gerda och hushållerskan överraskar dem i den intima situationen. Naima kliver obekymrat upp och vill genast börja med provningsbestyren, medan Sonja lojt ligger kvar i sängen:

Sonja gitte knappt röra sig, där hon låg med ögonens smala strim- 
mor svartglänsande mot hyns varma blekhet. Men när sidenet frasande föll över Naimas huvud buktade hon sin gossesmärta kropp och flyttade sig på kudden, så att hon kunde se vad som förehades. Ömsom kritik, ömsom beröm, oförbehållsamt båda. Och emellanåt ett råd, en anvisning, som alltid befanns höja effekten. Men rätt som det var kom det en nyans av skarpt ogillande i hennes mörkvarma alt:

- Du ska inte äta så mycket bakelser, och du bör inte dricka så väldiga kvantiteter starkt som du gör. Du blir alltför grov och fet, se där, din höft sväller ut som en soffpöl. (199-200)

I passagens början är det Sonjas kropp som fokuseras. Dess gossaktiga framtoning överensstämmer med dekadensens androgyna kvinnoideal. I sin nakenhet är det hon som är begärsobjektet, inte bara för Naima utan också för Gerda och läsaren. Men sedan börjar berättelsens kameraöga att registrera vad Sonja själv ser och hur hon reagerar på det hon ser. Det finns både begär och irritation i denna blick.

Samtalet kommer in på de båda kvinnornas yrke. Sonja berättar att Naima har varit på "räddningshem för skökor", varvid den senare blir rasande. Hon vill inte bli avslöjad och förnedrad inför Gerda. Men Sonja svarar:

- Ah, jag gör ju intet undantag för mig själv, vad är vi annat, sade Sonja lugnt. Hon roade sig med att suga röda fläckar på sin linjesköna arm. [...] Naima brast med ens i gråt.

- Odjur, du kan ta kol på en avgrundsande med ditt lugn och din elakhet. Om jag inte vore så gränslös kär i d -

Hon hejdades med en åtbörd, fick fatt i en parfymflaska och duggade Sonja riktigt. Gråten hade upphört lika fort som den kommit. (201)

Sonja, "som icke gjorde sig brått med klädseln, sedan hon lämnat sängen", uppträder i ena stunden som en blaserad femme fatale, väl medveten om den erotiska inverkan hon har på alla i sin omgivning, för att i nästa sätta stopp för det alltför intima. Hon tar på sig rol- 
len som sköka, men inte rollen som ... - ja, som vad då? "Morsan" kallar dem för "såna där", men det är osäkert om "sån där" betyder prostituerad, homosexuell, alkoholist eller lite av varje. Kanske kan man läsa in samtliga innebörder i "morsans" ord. I hel- eller halvpornografisk litteratur var kvinnlig homosexualitet, prostitution och drogmissbruk som regel intimt förknippade med varandra. Så är det i Emile Zolas Nana (1880) där författaren i naturalistisk anda skildrat det utsvävande livet vid teatrar och nöjesetablissemang, och så är det också i Victor Marguerittes La Garçonne (1922, Ungkarlsflickan), en roman som hade lånat en hel del från Nana och som var högaktuell när Sandel arbetade med sin roman. 1923 kom den i en svensk översättning gjord av journalisten, poeten och politikern Ture Nerman.

Naima sjunger och ackompanjerar sig själv på gitarr. Hennes repertoar omfattar såväl frälsningssånger som supvisor och hon uppträder iklädd endast underkläder och "de tunna muslinkalsongerna hade råkat brista bak". När hon börjar berätta minnen från sina utsvävningar i ungdomen tycker Sonja dock att det går för långt och bryter av hennes ordkaskader. Men Naima låter sig inte tystas utan hämnas genom att bli ännu mer vulgär:

- Vad fan nu då, kuttrade Naima med en lustig klippning i ögonlocken. Vem är det annars som är så pigg på att rota och rota i dem om inte du. Men nog kan jag tiga alltid. Kan fröken snörpa hop mig bak, jag menar byxorna förstås. (203)

Naima lovar att tiga om sina erfarenheter i samma andetag som hon ber Gerda att laga hennes kalsonger. Associationerna går som synes blixtsnabbt. Att såväl munnen som byxbaken ska snörpas ihop blir givetvis komiskt. Och tvetydigt. När Naima förtydligar saken med att det är byxan - och inte baken - som ska snörpas ihop övergår repliken från det tvetydiga till det skabrösa. Det handlar inte längre om minnen, utan om Naimas kalsonger och de kroppsdelar som bekläds av dem. När Naima sedan börjar tampas med polisen excellerar hon i tvetydighetens konst. Hon har en "giftgadd till tunga", förklarar berättaren. ${ }^{8}$ 
Samtalet vindlar sig fram och tillbaka, allt medan de tre kvinnorna är sysselsatta med klädprovning och sömnadsarbete. Någon ser i tysthet på någon. Blickar råkar mötas och någon tittar bort. Ett samtal tas upp, bryts av, tas upp igen och går i ny riktning. För det mesta är det den pratglada Naima som står för ordflödet, men Sonja har också en hel del att säga och Gerda blir mer och mer involverad i samtalet. Hon har blick för vad det är som ger Sonja "makt att behålla för alltid en vunnen kärlek".

Sonja är ofta elak mot Naima, för att hon saknar förfining, för att hon äter och dricker för mycket samtidigt som hon säljer sig för billigt, men Sonja sårar henne också genom att göra henne svartsjuk. Ändå är det uppenbart att det inte bara är Naima som är attraherad av Sonja, utan att begäret är ömsesidigt:

Sonja öppnade en bok, som hon hämtat ur sitt sovrum, men blev sittande utan att läsa, och följde Naimas rörelser med ögonen. Det var en vacker syn att se henne föra nålen. Hon hade åtagit sig fållningen. En pärla ett stygn, en pärla ... (212-213)

Om Naimas repliker nyss var grovkorniga, förknippas hon här med pärlor. Hennes personlighet liknar det arbete hon själv just har för händer: ett nålstygn - en pärla - ett nålstygn - en pärla. Men hon har ytterligare en roll att spela, en paradroll ska det visa sig, nämligen den handlingskraftiga och snabbtungade hjältinnan i en sängkammarfars. ${ }^{9}$ Det hela börjar med att en olyckssyster till dem kommer infarande i rummet, med sedlighetspolisen hack i häl. Den nyanlända kvinnan är livrädd. Tillsammans med hushållerskan gör kvinnorna hastigt upp en plan för hur de ska kunna rädda henne. Hon får helt enkelt krypa ner i Sonjas säng utklädd till karl. Naimas uppgift blir att prata omkull polismannen, en uppgift hon lyckas med på ett briljant sätt. Hon tar en ljuvlig hämnd för alla de gånger han har trakasserat henne och andra prostituerade kvinnor. Ställda inför det brutala förtryck som polismannen representerar uppstår det en spontan solidaritet mellan kvinnorna, och Gerda är lika delaktig i spektaklet som de andra, trots att hon ju inte tillhör deras föraktade skrå och trots att hon från början kände avsmak inför 
deras samkönade intimitet. Polismannens snöpliga sorti skildras på följande sätt:

De bugade honom ut med största artighet, men den uppskattade han till sitt rätta värde att döma efter avskedet. Han skakade nämligen sin käpp mot Naimas ansikte.

- Vi träffas nog igen och då ... sade han hotfullt.

Kommen några trappsteg ned vände han sig om, vilket han strax ångrade. Ty i dörröppningen stod Naima och räckte lång näsa, livligt men tyst applåderad av den hånleende fru Ekstrand. (225)

Eva Heggestad ser det lilla kvinnokollektiv som består av Naima, Sonja, hyresvärdinnan och hennes barn som en parallell till kollektivet Gerda, "morsan" och deras barn, en läsning som stöds av att kapitlen "I morsans hägn", som handlar om hur Gerda och "morsan" blir vänner, och "Hetärer", som handlar om Sonja och Naima, är romanens i särklass längsta kapitel. Det första kollektivet hålls samman av vänskap och solidaritet, medan det andra är uppbyggt kring sexualitet. Också där finns det skärvor av solidaritet, men vänskapen mellan "morsan" och Gerda visar sig i längden vara mer pålitlig än det erotiska begär som finns mellan Sonja och Naima. Berättelsen lyfter fram vänskapen som ett socialt fundament på vilket nya familjekonstellationer kan byggas.

I berättelsen om de prostituerade kvinnorna finns det undanträngda begäret. Heterosexualitet existerar här bara som kommersialiserad promiskuitet, medan den egentliga erotiken finns mellan kvinnorna. "Morsan" är kritisk till de prostituerades livsföring och Gerda känner vämjelse inför den - det hade knappast varit möjligt att skildra samkönad sexualitet så öppet som faktiskt sker i denna roman utan ett tydligt avståndstagande - men ändå är det förbjudnas lockelse uppenbar: för Gerda, vars blod börjar sjuda i de båda hetärernas närhet, och för läsaren, som inbjuds att ta del av pikanta detaljer från deras vardagsliv. Och i konfrontationen mellan polismakten och de prostituerade kvinnorna, ja där är det på kvinnornas sida som berättelsen står. 